\title{
Measures to control protracted large Lassa fever outbreak in Nigeria, 1 January to 28 April 2019
}

Chioma C. Dan-Nwafor ${ }^{1,2}$, Yuki Furuse ${ }^{2,3,4}$, Elsie A llori ${ }^{1}$, Oladipupo Ipadeola ${ }^{5}$, Kachikwulu 0 Akabike ${ }^{1}$, Anthony Ahumibe ${ }^{1}$, Winifred Ukponu ${ }^{6}$, Lawal Bakare ${ }^{1}$, Tochi J Okwor ${ }^{1}$, Gbenga Joseph ${ }^{1}$, Nwando G Mba ${ }^{1}$, Adejoke Akano ${ }^{1}$, Adebola T Olayinka ${ }^{3}$, Ihekerenma Okoli ${ }^{7}$, Rita A Okea ${ }^{8}$, Favour Makava9, Nkem Ugbogulu ${ }^{10}$, Saliu Oladele ${ }^{3}$, Geoffrey Namara ${ }^{3}$, Esther N Muwanguzi ${ }^{3}$, Dhamari Naidoo ${ }^{3}$, Samuel K Mutbam³ , Ifeanyi Okudo ${ }^{3}$, Solomon F Woldetsadik ${ }^{3}$, Clement LP Lasuba ${ }^{3}$, Chikwe Ihekweazu ${ }^{1}$

1. Nigeria Centre for Disease Control, Abuja, Nigeria

2. These authors contributed equally to this work

3. World Health Organization, Abuja, Nigeria

4. Institute for Frontier Life and Medical Sciences, Kyoto University, Kyoto, Japan

5. United States Centers for Disease Control and Prevention, Abuja, Nigeria

6. Georgetown University, Washington DC, United States of America

7. Federal Ministry of Agriculture and Rural Development, Abuja, Nigeria

8. Federal Ministry of Environment, Abuja, Nigeria

9. Maryland Global Initiatives Corporation, Abuja, Nigeria

10. Pro Health International, Abuja, Nigeria

Correspondence: Chikwe Ihekweazu (chikwe.ihekweazu@ncdc.gov.ng)

Citation style for this article:

Dan-Nwafor Chioma C., Furuse Yuki, Ilori Elsie A, Ipadeola Oladipupo, Akabike Kachikwulu O, Ahumibe Anthony, Ukponu Winifred, Bakare Lawal, Okwor Toch J, Joseph Gbenga, Mba Nwando G, Akano Adejoke, Olayinka Adebola T, Okoli Ihekerenma, Okea Rita A, Makava Favour, Ugbogulu Nkem, Oladele Saliu, Namara Geoffrey, Muwanguzi Esther N, Naidoo Dhamari, Mutbam Samuel K, Okudo Ifeanyi, Woldetsadik Solomon F, Lasuba Clement LP, Ihekweazu Chikwe. Measures to control protracted large Lassa fever outbreak in Nigeria, 1 January to 28 April 2019. Euro Surveill. 2019;24(20):pii=1900272. https://doi.org/10.2807/1560-7917. ES.2019.24.20.1900272

Lassa fever cases have increased in Nigeria since 2016 with the highest number, 633 cases, reported in 2018. From 1 January to 28 April 2019, 554 laboratoryconfirmed cases including 124 deaths were reported in 21 states in Nigeria. A public health emergency was declared on 22 January by the Nigeria Centre for Disease Control. We describe the various outbreak responses that have been implemented, including establishment of emergency thresholds and guidelines for case management.

Lassa fever is endemic in Nigeria. From 1 January 2019 (week 1) to 28 April 2019 (week 17), 554 laboratoryconfirmed Lassa fever cases including 124 deaths were reported from 21 of 37 states/territory in Nigeria. On 22 January, Nigerian public health authorities declared the outbreak and emergency. Here, we describe the current situation and implemented response to the outbreak.

\section{Current outbreak and surveillance of Lassa fever}

From 2016 to $2018,177,312$ and 633 confirmed Lassa fever cases were reported, respectively, in Nigeria. While the outbreak recorded the largest ever number of cases in 2018, the number of confirmed cases between 1 January and 28 April 2019 has surpassed that of the corresponding period in 2018; the number of suspected cases, including laboratory-negative cases, also surpassed that for the same period (Table and Figure). Blood samples were collected for all suspected cases and tested for Lassa fever using reverse transcription
PCR. Positivity rate among suspected cases in this outbreak was $24 \%$, similar to that of previous years (Table). The increase in confirmed cases in 2019 could result, at least partially, from improved disease surveillance systems.

The main reservoir for of Lassa fever virus is rodents and humans can be infected by contact with infected animals or their excretions, although human-to-human transmission is possible and sporadically reported [1]. Analysis of viral genomic sequence of samples collected in 2019 revealed that the main source of infection is spill over from rodents [2].

The Nigeria Centre for Disease Control (NCDC) was established in 2011 and has strengthened the surveillance system for infectious diseases, including Lassa fever [3]. On 22 January 2019, the NCDC declared the Lassa fever outbreak an emergency in response to the high case numbers. Surveillance training was provided for public health officers at both national and state levels. Sensitisation to increase suspicion of the disease was conducted for healthcare workers through workshops and for the general public through media such as radio, television, poster and social network services. Strengthening of laboratory capacity and sample transportation system has also facilitated disease detection and reporting through establishment of the Lassa fever laboratory network. 
Summary of statistics of Lassa fever outbreak in Nigeria, 1 January 2017-28 April 2019 ( $\mathrm{n}=1,499$ confirmed cases)

\begin{tabular}{|c|c|c|c|c|c|c|c|c|c|c|c|c|c|}
\hline \multirow[b]{2}{*}{ Week } & \multirow{2}{*}{$\begin{array}{l}\text { Total suspected } \\
\text { cases }\end{array}$} & \multirow{2}{*}{$\begin{array}{l}\text { Positive } \\
\text { rate (\%) }\end{array}$} & \multicolumn{11}{|c|}{ Confirmed cases } \\
\hline & & & Total & Deaths & $\begin{array}{c}\text { Case-fatality } \\
\text { rate }(\%)\end{array}$ & $\begin{array}{l}\text { Healthcare } \\
\text { workers }\end{array}$ & $\begin{array}{l}\text { Ebonyi } \\
\text { state }\end{array}$ & $\begin{array}{l}\text { Edo } \\
\text { state }\end{array}$ & $\begin{array}{l}\text { Ondo } \\
\text { state }\end{array}$ & $\begin{array}{l}\text { Bauchi } \\
\text { state }\end{array}$ & $\begin{array}{c}\text { Plateau } \\
\text { state }\end{array}$ & $\begin{array}{l}\text { Taraba } \\
\text { state }\end{array}$ & $\begin{array}{l}\text { Other } \\
\text { states }\end{array}$ \\
\hline \multicolumn{14}{|l|}{2017} \\
\hline $1-17$ & 462 & 32 & 149 & 53 & 36 & NA & 5 & 56 & 23 & 6 & 8 & 23 & 28 \\
\hline $1-52$ & 1,030 & 30 & 312 & 78 & 25 & NA & 5 & 116 & 77 & 13 & 21 & 24 & 56 \\
\hline \multicolumn{14}{|l|}{2018} \\
\hline $1-17$ & 1,891 & 22 & 420 & 106 & 25 & 37 & 63 & 176 & 99 & 10 & 9 & 19 & 44 \\
\hline $1-52$ & 3,506 & 18 & 633 & 171 & 27 & 45 & 72 & 279 & 159 & 24 & 14 & 23 & 62 \\
\hline \multicolumn{14}{|l|}{2019} \\
\hline $1-17$ & 2,323 & 24 & 554 & 124 & 22 & 18 & 44 & 197 & 155 & 42 & 35 & 38 & 43 \\
\hline
\end{tabular}

NA: not available.

\section{FIGURE}

Number of Lassa fever cases in Nigeria by calendar week, 1 January 2016-28 April 2019 ( $\mathrm{n}=1,685$ confirmed cases)

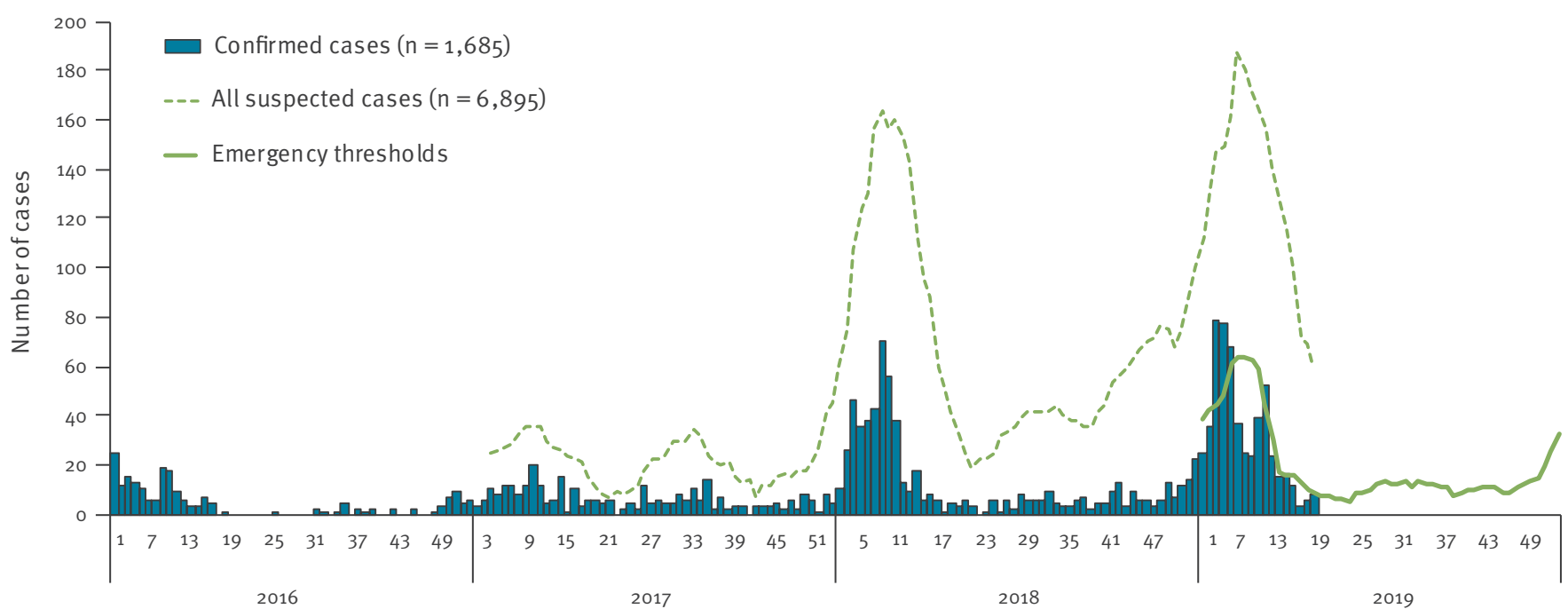

Week and year

Weekly numbers of confirmed cases from 2016-19, all suspected cases including confirmed and laboratory-negative cases from 2017-19 and emergency thresholds for 2019 were plotted. Data of all suspected cases in 2016 were not available.

\section{Clinical management and new guidelines}

The fatality rate among confirmed cases was $22 \%$ (124/554) in 2019. National and zonal workshops for clinical management of Lassa fever patients were convened as a part of outbreak response. Furthermore, national guidelines to treat Lassa fever patients were reviewed and updated in November 2018, to include infection prevention and control (IPC) measures, guidance on clinical treatment and care of complications after Lassa fever infection e.g. septic shock and kidney injury [4]. These recommendations arose following findings that such complications are important risk factors for fatal outcome among Lassa fever patients [5].
Unfortunately, there has been no substantial change in the case-fatality rate over the past 3 years (Table). Familiarising healthcare workers with the new guidelines and helping them to better detect and treat Lassa virus earlier [6], should help improve the prognosis and reduce the mortality of the disease.

Healthcare workers are at risk of infection from Lassa fever patients when adherence to IPC is poor [1]. In 2019, there have been 18 healthcare workers infected with Lassa fever (as at 28 April). In the guidelines, a full set of personal protective equipment is recommended for healthcare workers who provide direct 
patient care to suspected or confirmed Lassa fever patients. While necessary supplies have been distributed to Lassa fever treatment centres in 2019 (due to improved communication and logistics system in the country), the resource-limited setting in Lassa fever endemic areas is still challenging in terms of feasibility and sustainability.

\section{Determining thresholds for emergency detection}

As Lassa fever is endemic in Nigeria and cases are reported every year, it becomes more important to monitor changes in the trend of infection or an abnormally high number of cases. With this in mind, emergency designation criteria thresholds were developed using statistical criteria that account for expected epidemiology of disease patterns in Nigeria (Figure). Briefly, the threshold was developed as the mean plus two standard deviations of the weekly number of confirmed cases for the period of 2 weeks before and 2 weeks after the week of interest over the past 3 years (i.e. data from 2016 to 2018 for the development of thresholds for 2019). Although the methodology did not use environmental variables e.g. rainfall and population of rodents, the thresholds captured seasonal fluctuation by referring to historical data. By monitoring exceedances of current case numbers against these thresholds, abnormal trends can be identified to determine the emergency phase of outbreak.

\section{Situation and potential of domestic and international spread of the disease}

The majority of confirmed cases $(396 / 554,71 \%)$ in 2019 were reported from three states with standard Lassa fever treatment centres (Ebonyi, Edo and Ondo); Lassa fever treatment centres are also situated in other states. It is unknown whether the prevalence of Lassa fever was considerably high in those three states, whether there was heightened suspicion of Lassa fever enforcing local surveillance activity, or both. Interestingly, other states e.g. Bauchi, Plateau and Taraba, showed the highest historical number of cases in each state in 2019 (Table). This also makes the situation in 2019 unusual and could suggest emergency measures are required.

Lassa fever was included as a notifiable disease under the International Health Regulations due to its epidemic prone nature and potential to cause economic and social disruption [7]. There was a probable exportation of Lassa fever cases from Nigeria to Benin in 2018. Three confirmed cases were reported in Benin who had migrated from Nigeria to Benin just before the detection of the disease (data not shown). Although exportation of Lassa fever cases has not been reported so far in 2019, confirmed cases were reported in Nigerian states adjacent to Benin, Cameroon and Niger.

Nigeria is the host of the West African regional coordinating centre of the Africa Centres for Disease Control and Prevention (Africa CDC, Addis Ababa, Ethiopia) recently established in 2017 [8], this means that there is a strong collaborative relationship with the NCDC. Although there was no deployment need from the Africa CDC during the Lassa fever outbreak in 2019, there had been deployments to support Lassa fever response in Nigeria, in 2017. In 2019, the regional body supported through virtual meetings, to understand the situation in Nigeria and assess the level of risk to other African countries.

The main outbound travel destinations from Nigeria to Europe include France and the United Kingdom (UK) [9], and the number of travellers from the UK to Nigeria are ca150,000 per year (second only to Niger). Given the overall large number of international flights from Nigeria, exportation of the disease outside of the African continent including European countries is possible in theory. Still, the World Health Organization does not recommend any travel or trade restriction to Nigeria based on the currently available information [10].

Healthcare workers outside Nigeria should be aware of the situation in case they receive patients with compatible clinical symptoms and history of a stay in areas in Nigeria where there is transmission of the disease.

\section{Conclusion}

Here, we described the situation of the Lassa fever outbreak in Nigeria as at 28 April 2019. In addition to the improved surveillance system, there could be climatic or ecological conditions influencing the large waves in 2018 and 2019. Utilisation of data of environmental factors will possibly allow us to predict outbreaks of the disease in the future. We must remain vigilant and keep improving disease surveillance and clinical management for future outbreaks. Healthcare workers must have a high index of suspicion of the disease and adhere to IPC measures while providing care for all patients. Familiarising health care workers with the new guidelines mentioned above is also important to minimise the risk of nosocomial transmission of Lassa fever.

\section{Acknowledgements}

We thank all who fought against this outbreak, including those at the healthcare facilities, Lassa fever diagnostic laboratories, and Nigeria Centre for Disease Control. Outbreak responses were implemented with technical support from Africa Centres for Disease Control and Prevention, African Field Epidemiology Network, Alliance for International Medical Action, Bernhard Nocht Institute, Global Outbreak Alert and Response Network, Public Health England, Robert Koch Institute, United Kingdom Public Health Rapid Support Team, United Nations Children's Fund, United States Centers for Disease Control and Prevention, and World Health Organization (WHO) and financial support from European Civil Protection and Humanitarian Aid Operations, WHO, and World Bank. The laboratory network was supported by Bernhard Nocht Institute, Foundation for Innovative New Diagnostics, Japan International Cooperation Agency, University of Maryland Baltimore, WHO, and World Bank. We 
also express our sincerest condolences to the families and friends of those who died during the outbreak.

\section{Conflict of interest}

None declared.

\section{Authors' contributions}

Principal investigator: CCD-N. Outbreak response including data collection: CCD-N, YF, EAI, OI, KOA, AA, WU, LB, TJO, GJ, NGM, AA, ATO, IO, RAO, FM, NU, SO, GN, ENM, DN, SKM, IO, SFW, CLPL, and Cl. Epidemiological data analysis: CCD-N, $\mathrm{YF}$, and OI. Preparation of first draft: CCD-N, YF, EAI, and $\mathrm{CI}$. Draft revision and approval: all authors.

\section{References}

1. Richmond JK, Baglole DJ. Lassa fever: epidemiology, clinical features, and social consequences. BMJ. 2003;327(7426):12715. https://doi.org/10.1136/bmj.327.7426.1271 PMID: 14644972

2. Günther S. 2019 Lassa virus sequencing in Nigeria - Final field report (75 samples). Edinburgh: Virological; 2019. Available from: http://virological.org/t/2019-lassa-virus-sequencing-innigeria-final-field-report-75-samples/291

3. Maxmen A. This Nigerian doctor might just prevent the next deadly pandemic. Nature. 2019;566(7744):310-3. https://doi. org/10.1038/d41586-019-00615-x PMID: 30787458

4. Nigeria Centre for Disease Control (NCDC). National Guidelines for Lassa fever case Management. Abuja: NCDC; 2018. Available from: https://ncdc.gov.ng/themes/common/docs/ protocols/92_1547068532.pdf

5. Okokhere P, Colubri A, Azubike C, Iruolagbe C, Osazuwa O, Tabrizi S, et al. Clinical and laboratory predictors of Lassa fever outcome in a dedicated treatment facility in Nigeria: a retrospective, observational cohort study. Lancet Infect Dis. 2018;18(6):684-95. https://doi.org/10.1016/S14733099(18)30121-X PMID: 29523497

6. McCormick JB, King IJ, Webb PA, Scribner CL, Craven RB, Johnson KM, et al. Lassa fever. Effective therapy with ribavirin. N Engl J Med. 1986;314(1):20-6. https://doi.org/10.1056/ NEJM198601023140104 PMID: 3940312

7. World Health Organization (WHO). International Health Regulations. Geneva: WHO; 2005 . Available from: https://apps. who.int/iris/bitstream/handle/10665/246107/9789241580496eng.pdf;jsessionid=7AD9710AEB4529F3302DoE8B18C21D3D?s equence $=1$

8. Africa Centres for Disease Control and Prevention. Addis Ababa: Africa CDC; [Accessed 10 May 2019]. Available from: http://www.africacdc.org/

9. WESGRO Cape town and Western cape tourism, trade \& investment. Tourism. Nigeria. Tourism Market Insights 2017. Cape Town \& Western Cape: WESGRO; 2017. Available from: http://www.wesgro.co.za/pdf_repository/Tourism Market Insights Nigeria 2017.pdf.

10. World Health Organization (WHO). Lassa Fever - Nigeria. Geneva: WHO; 2019. Available from: https://www.who.int/csr/ don/14-february-2019-lassa-fever-nigeria/en/

\section{License, supplementary material and copyright}

This is an open-access article distributed under the terms of the Creative Commons Attribution (CC BY 4.0) Licence. You may share and adapt the material, but must give appropriate credit to the source, provide a link to the licence and indicate if changes were made.

Any supplementary material referenced in the article can be found in the online version.

This article is copyright of the authors or their affiliated institutions, 2019. 